\title{
Zastosowanie implantu ucha środkowego Vibrant Soundbridge u dziecka z zespołem Goltza-Gorlina $z$ jednostronną atrezją przewodu słuchowego zewnętrznego i niedosłuchem typu mieszanego
}

\section{Application of the middle ear implant Vibrant Soundbridge in a child with Goltz-Gorlin syndrome with unilateral congenital atresia and mixed hearing loss}

\author{
Henryk Skarżyński ${ }^{1,2}$, Marek Porowski ${ }^{1,2}$ \\ ${ }^{1}$ Instytut Fizjologii i Patologii Słuchu, ul. Zgrupowania AK „Kampinos” 1, 01-943 Warszawa \\ ${ }^{2}$ Światowe Centrum Słuchu, ul. Mokra 17, Kajetany, 05-830 Nadarzyn
}

Adres autora: Marek Porowski, Instytutu Fizjologii i Patologii Słuchu, ul. Zgrupowania AK „Kampinos” 1, 01-943 Warszawa; e-mail: m.porowski@ifps.org.pl

\section{Streszczenie}

Cel: celem pracy było przedstawienie procedury chirurgicznej oraz wyników zastosowania implantu ucha środkowego Vibrant Soundbridge u dziecka płci żeńskiej z zespołem Goltza-Gorlina z obustronnym asymetrycznym niedosłuchem mieszanym oraz wadą ucha zewnętrznego i środkowego w postaci mikrocji, atrezji przewodu słuchowego zewnętrznego oraz złożonej wady kosteczek słuchowych.

Metoda: w leczeniu niedosłuchu zastosowano wszczepienie implantu ucha środkowego Vibrant Soundbridge z zakotwiczeniem przetwornika FMT na zdeformowanym bloku kosteczek słuchowych z dojścia przez antromastoidektomię i attykotomię tylną.

Wyniki: wyniki wczesne oraz po 2-letniej obserwacji są bardzo dobre. Nie zaobserwowano powikłań podczas operacji oraz $\mathrm{w}$ przebiegu procesu gojenia. Pooperacyjne badanie audiometrii tonalnej nie wykazało zmian w stosunku do badania sprzed operacji.

\begin{abstract}
Wnioski: Vibrant Soundbridge jest bardzo dobrym rozwiązaniem w złożonych wadach ucha zewnętrznego i środkowego, w tym w zespole Goltza-Gorlina. Procedura otochirurgiczna wymaga dużego doświadczenia, które pozwoli w różnym stopniu niedorozwoju ucha środkowego na jego bezpieczne otwarcie, uruchomienie istniejącego w całości lub części łańcucha kosteczek słuchowych i umocowanie zakończenia elektrody stymulującej (przetwornika FMT).
\end{abstract}

Słowa kluczowe: zespół Goltza • zespół Goltza-Gorlina • Focal Dermal Hypoplasia • Vibrant Soundbridge

Abstract

Aim: the aim of the study was to present the surgical procedure and the results of Vibrant Soundbridge middle ear implant application in a girl child with Goltz-Gorlin syndrome with bilateral asymmetric mixed hearing impairment and the malformation of outer and middle ear involving microtia, external auditory meatus atresia and complex malformation of ossicles.

Method: in the treatment of the hearing impairment the Vibrant Soundbridge middle-ear implant with fixation of the FMT (activator) on the malformed ear ossicles' block, with the approach through the antromastoidectomy and posterior atticotomy, was used.

Results: the early results and those after 2-years observation are very good. No complications during the surgery, nor during the healing process were observed. Postoperative pure tone audiometry did not reveal any changes with relation to the test made before the operation. 
Conclusions: Vibrant Soundbridge is a very good solution in complex malformations of outer and middle ear, including the Goltz-Gorlin syndrome. Otosurgical procedure requires much experience, which will enable safe opening of middle ear with malformations of different degree, in order to activate the existing - in whole or in part - chain of ossicles, and to fix FMT.

Key words: Goltz syndrome • Goltz-Gorlin syndrome • Focal Dermal Hypoplasia • Vibrant Soundbridge

\section{Wstęp}

Zespół Goltza, inaczej Goltza-Gorlina czy Focal Dermal Hypoplasia to niezwykle rzadki zespół wad genetycznych charakteryzujący się przede wszystkim zaburzeniami budowy tkanki łącznej wynikającymi z nieprawidłowej budowy kolagenu IV. Po raz pierwszy został opisany przez Libermanna [1] w 1935 roku, następnie Goltz [2] w roku 1962 i Gorlinc [3] w 1963 podali dokładną charakterystykę kliniczną. Częstość występowania nie jest dokładnie znana a do tej pory w literaturze opisano zaledwie około 300 przypadków tego zespołu, w zdecydowanej większości u dziewczynek.

Chorzy cierpią od najmłodszych lat na niegojące się owrzodzenia i zmiany skórne. Są to plamy skórne z brakiem pigmentacji, ścieńczenie skóry, zmiany brodawczakowate związane głównie z okolicami głowy i szyi, które mogą mieć związek z zakażeniem wirusem ludzkiego brodawczaka. Zmianom tym towarzyszą zaburzenia układu kostno-stawowego dotyczące przede wszystkim palców rąk i stóp jako dodatkowe palce, braki czy zrosty obecnych (polidaktylia, oligodaktylia, syndaktylia), rozszczepy podniebienia, częściowa lub całkowita utrata owłosienia głowy, zaburzenia zębów, paznokci i inne rzadsze [4-10].

Dziedziczenie zespołu Goltza ma charakter dominujący, związany z chromosomem X [11,12]. Mutacje genowe, które pojawiają się zwykle de novo są letalne u osobników płci męskiej prawie zawsze [13], choć opisywane są bardzo nieliczne przypadki również u chłopców [14,15] a także występowanie rodzinne $[16,17]$.

Zaburzenia narządu słuchu w FDHS mogą obejmować zarówno ucho zewnętrzne, środkowe jak i wewnętrzne. Chorzy prezentują niedosłuch o charakterze przewodzeniowym, odbiorczym lub mieszanym. W poszczególnych przypadkach zespołu zaobserwowano: różnego stopnia deformacje małżowiny usznej, atrezję przewodu słuchowego zewnętrznego, przewlekłe wysiękowe zapalenie ucha środkowego, dodatkowe wyrośla przeduszne, przewlekłe perlakowe zapalenie ucha, malformacje ucha wewnętrznego, zaburzenia nerwu przedsionkowo-ślimakowego i inne [10].

Vibrant Soundbridge należy do wszczepialnych implantów ucha środkowego. Korzyści z jego stosowania w przypadkach niedosłuchu różnego pochodzenia u osób dorosłych już od wielu lat wielokrotnie były wykazywane. Wskazania do implantacji obejmują niedosłuch zmysłowo-nerwowy jak również mieszany i przewodzeniowy w przypadkach po licznych nieudanych ossikuloplastykach czy operacjach radykalnych zmodyfikowanych a także w wadach wrodzonych. Vibrant Soundbridge jako jedyny implant ucha środkowego jest zarejestrowany do stosowania również u dzieci. Proces wyboru metody terapeutycznej $\mathrm{w}$ tym konkretnym przypadku przedstawiono poniżej w dyskusji.

\section{Opis przypadku}

Dziecko płci żeńskiej, ur. 2001 r, z rozpoznanym zespołem Goltza-Gorlina i typowymi jego objawami hospitalizowane było w Instytucie Fizjologii i Patologii Słuchu w roku 2005, 2006 oraz 2010. Objawy obejmowały zmiany skórne, mnogie wykwity grudkowe, zlewające się zwłaszcza w okolicy bródki po stronie prawej, kąta oka oraz szyi. Wykwity te powiększały się z wiekiem, były bolesne, ropiejące $\mathrm{z}$ nieustannym stanem zapalnym $\mathrm{w}$ ich obrębie. W leczeniu miejscowym wykwitów skórnych zastosowano laser CO2 uzyskując znaczne zmniejszenie dolegliwości bólowych oraz ustąpienie stanu zapalnego, w obrazie pojawiły się blizny blednące wraz z upływem czasu i procesu gojenia. Badanie histopatologiczne pobranego materiału podczas operacji dało wynik: Papilloma in statu inflammationis chronicae.

Nieprawidłowości narządu słuchu dotyczyły ucha zewnętrznego i środkowego prawego w postaci mikrocji i zwężenia przewodu słuchowego zewnętrznego oraz przewlekłego wysiękowego zapalenia ucha środkowego lewego. Niedosłuch u dziecka potwierdzono w badaniach obiektywnych i subiektywnych: ABR, audiometria tonalna, audiometria impedancyjna, TOAE. Obecność wady wrodzonej ucha środkowego prawego została potwierdzona na podstawie wyniku tomografii komputerowej kości skroniowych.

Na podstawie całości obrazu klinicznego podjęto początkowo decyzję o tympanotomii eksploratywnej ucha prawego. Zabieg wykonano w 2006 roku u 5-letniego wówczas dziecka, stwierdzając zwężenie przewodu słuchowego zewnętrznego, w uchu środkowym pozapalne zmiany zarostowe, które usunięto, dodatkowo potwierdzono ankylozę I i II kosteczki słuchowej, brak kostnego kanału nerwu twarzowego i jego odsłonięcie w odcinku bębenkowym. Wobec braku możliwości rekonstrukcyjnych na tym etapie oraz biorąc pod uwagę dobry słuch w drugim uchu, decyzję o ewentualnej kolejnej operacji odłożono do czasu, gdy dziecko będzie starsze. Ze względu na obecność wysięku oraz zmian zarostowych w lepiej słyszącym lewym uchu wykonano tympanotomię $\mathrm{z}$ usunięciem zmian zarostowych z jamy bębenkowej oraz założono dren wentylacyjny.

W roku 2009 ponownie dokonano oceny możliwości poprawy słuchu, wykonano ponownie badanie HRCT, potwierdzono w opisie badania w uchu prawym zmieniony przebieg kanału nerwu twarzowego, hipoplazję kosteczek słuchowych, zwłaszcza I i II, hipoplastyczny staw kowadełkowo-strzemiączkowy, strzemię zachowane i prawidłowe. Młoteczek i kowadełko były zrośnięte razem a młoteczek dodatkowo przytwierdzony do kostnej przegrody obecnej w uchu środkowym. Nieprawidłowy i kręty przewód słuchowy otaczała miękkotkankowa zmiana powodująca jego zwężenie. Przyjmując, że potencjalne manipulacje w okolicy strzemiączka oraz nerwu twarzowego wiązałyby się 


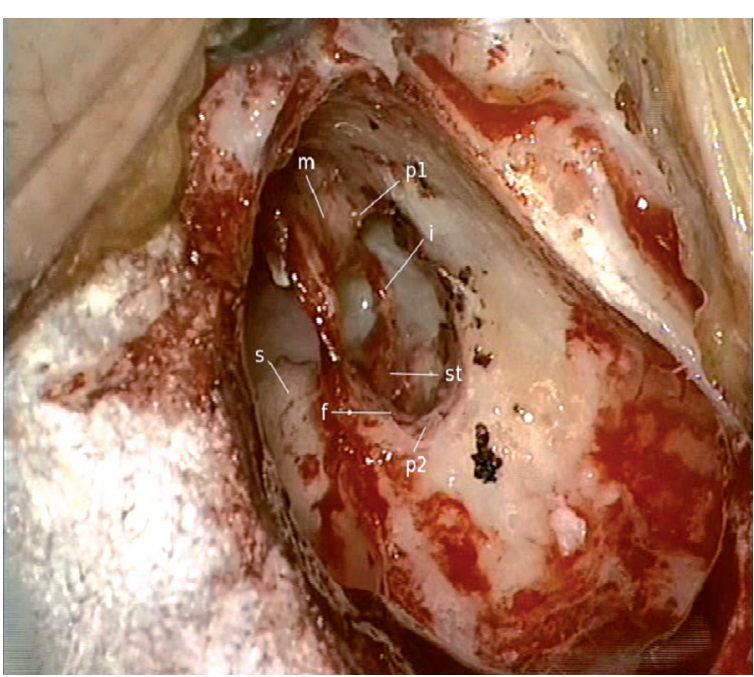

Rycina 1. m - blok młoteczka i kowadełka; i - staw kowadełkowo-strzemiączkowy; s - kanał półkolisty boczny; f - nerw twarzowy; strzemiączko; p1 - wyżłobienie w bloku kosteczek jako miejsce zapięcia FMT; p2: wyżłobienie w kości do umieszczenia tam przetwornika

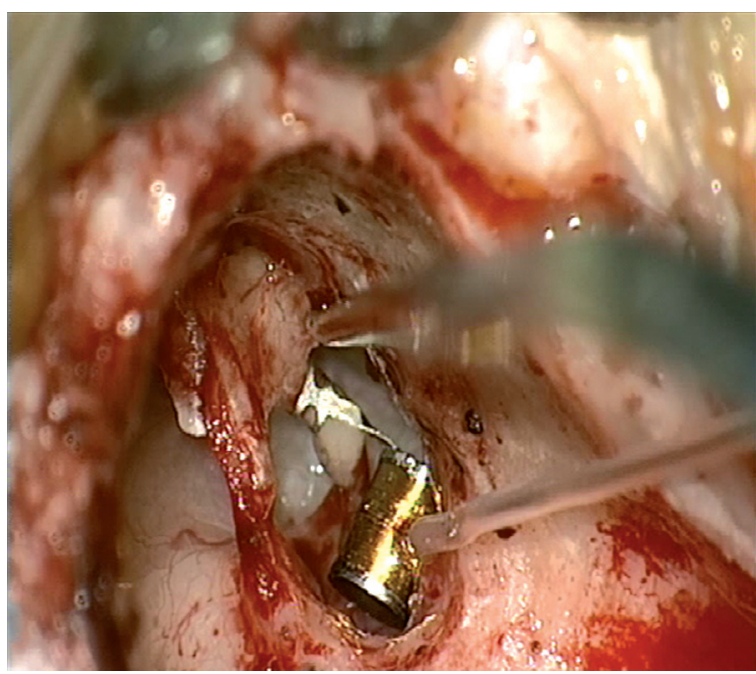

Rycina 2. Stan po założeniu i zapięciu urządzenia. Widoczny przetwornik z zapięciem na resztkowych kosteczkach oraz ufiksowanie z użyciem cementu szkłojonomerycznego

z dużym ryzykiem jego podrażnienia i uszkodzenia oraz nie mając pewności co do trwałości wykonanej ossikuloplastyki, jak również duże ryzyko zarastania i tak już wąskiego przewodu słuchowego zewnętrznego podjęto decyzję o zaimplantowaniu dziecka wykorzystując implant ucha środkowego Vibrant Soundbridge firmy Med-El. Według najlepszej wiedzy Autorów było to pierwsze na świecie tego typu zastosowanie urządzenia w zespole Goltza.

\section{Metoda}

Operację wykonano w kwietniu 2010 roku. Dostęp operacyjny typowy z cięcia za małżowiną uszną. Nie planowano w przyszłości operacji rekonstrukcyjnej małżowiny usznej w związku z czym cięcie poprowadzono dokładnie w rowku zamałżowinowym. Wykonano antromastoidektomię, otworzono mały, powietrzny wyrostek sutkowy. Wykonano $\mathrm{z}$ kolei attykotomię tylną, poszerzono ją i uwidoczniono

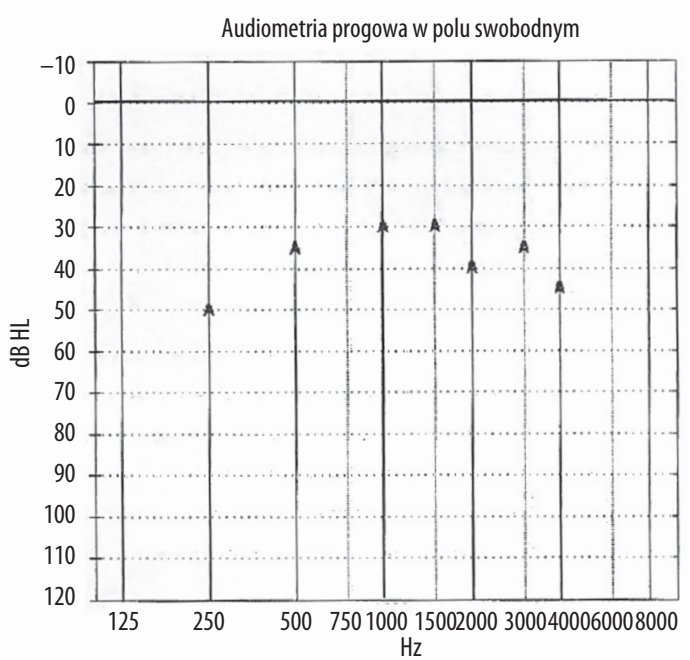

A - w aparacie(-ach); S - bez aparatu (-ów)

Rycina 3. Wynik audiometrii progowej w polu swobodnym

poszczególne kosteczki słuchowe. Stwierdzono, że młoteczek był w ścisłym połączeniu ze zdeformowanym kowadełkiem tworząc jeden blok, który dodatkowo był ufiksowany przez zrost kostny ze ścianą attyki. Etapowo za pomocą frezy diamentowej o małej średnicy usuwano nadmiar tkanki kostnej uwidaczniając coraz lepiej kosteczki, dotarto do stawu kowadełkowo-strzemiączkowego, który choć zdeformowany i cienki to jednak zachowywał swoją funkcję (Rycina 1). Uruchomiono młoteczek usuwając fragment kostny go blokujący. Następnie poszerzono kość nad nerwem twarzowym tworząc wystarczająco duże zagłębienie dla przetwornika FMT. W bloku kosteczek wytworzono zagłębienie przygotowane do zapięcia przetwornika. Po przygotowaniu typowej loży w kości skroniowej dla części wewnętrznej implantu oraz dla elektrody, FMT umieszczono na odnodze długiej kowadełka w bliskim sąsiedztwie ze stawem kowadełkowo-strzemiączkowym. FMT delikatnie zapięto na kosteczce a następnie użyto cement szkłojonomeryczny aby zapobiec przesunięciu się go ze zniekształconych kosteczek (Rycina 2). Dalsza procedura stosowana w Instytucie jest typowa dla tego typu zabiegów i składa się z umocowania cementem szkłojonomerycznym części wewnętrznej implantu, zamknięcia jamy wyrostka sutkowego za pomocą fragmentów Curasponu nasączonych antybiotykiem $\mathrm{z}$ dodatkowym ustabilizowaniem za pomocą kleju tkankowego oraz zamknięcia wyrostka sutkowego płytką kostną kości skroniowej pobraną na samym początku operacji.

\section{Wyniki}

Wczesny i późny przebieg pooperacyjny niepowikłany. Po trzech dniach pobytu w Instytucie dziecko zostało wypisane do domu. Gojenie rany pooperacyjnej oceniono jako bardzo dobre. Zdjęcie szwów wykonano 10 dni po wszczepieniu urządzenia obserwując prawidłowe gojenie rany. Procesor zewnętrzny oraz wstępne jego ustawienia, po wygojeniu rany zostało przeprowadzone miesiąc po operacji. W czasie wizyt kontrolnych przeprowadzono ustawienia procesora implantu, wykonano ćwiczenia słuchowe $\mathrm{z}$ wykorzystaniem audiometrii wolnego pola oraz dokonano 


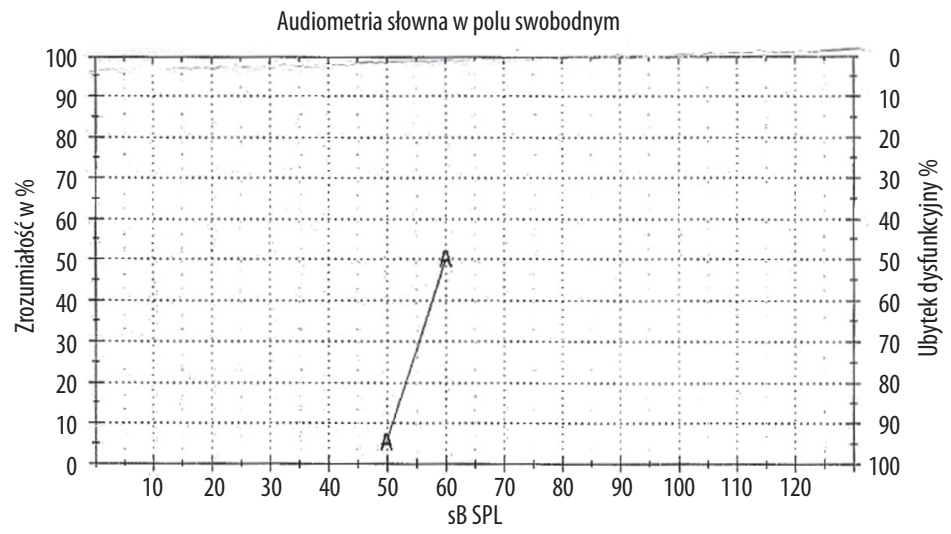

Rycina 4. Wynik audiometrii słownej w polu swobodnym

\section{A - w aparacie(-ach); S - bez aparatu (-ów) \\ AN - w aparacie(-ach) z szumami; S - bez aparatu (-ów) z szumami}

Dopasowanie aparatu (konrtola)

kontrola i regulacja vsb UP

$U L$ - masker

oceny korzyści z zastosowania urządzenia (Ryciny 3 i 4). Ostatnia wizyta w Instytucie miała miejsce w kwietniu 2012 r. a więc dwa lata po operacji. Subiektywnie, w ocenie matki oraz samej pacjentki korzyści są znaczne i utrzymują się w ciągu tego okresu, dziecko nosi aparat bardzo chętnie.

\section{Dyskusja}

Zastosowanie implantu ucha środkowego w wadach wrodzonych u dzieci nie jest metodą standardową i powszechnie stosowaną. Do tej pory ukazało się w literaturze zaledwie kilka prac oraz doniesień zjazdowych dotyczących tego tematu [19-21]. Po części wynikało to z braku rejestracji tego urządzenia dla zastosowań u młodych pacjentów, co się zmieniło niedawno i można je stosować również u dzieci. Nieprzewidywalność wad wrodzonych ucha środkowego i zewnętrznego, nieprawidłowy przebieg nerwu twarzowego i innych struktur w zdeformowanym uchu skłania wielu otochirurgów raczej do zastosowania innych rozwiązań niż implanty ucha środkowego, takich jak aparaty na przewodnictwo kostne, które w wielu wypadkach stanowią optymalne rozwiązanie, jednak mają również wady. Z drugiej strony brak rozsądnych alternatyw powoduje, że coraz częściej chirurdzy sięgają po implant ucha środkowego, również u dzieci najmłodszych. Operacje rekonstrukcyjne atrezji przewodu słuchowego zewnętrznego obarczone są stosunkowo dużym ryzykiem, wymagają najczęściej wielu znieczuleń i często są rozczarowujące zarówno dla chirurga jak i dla chorego. Najlepsze ośrodki na świecie nie mają dobrych wyników leczenia chirurgicznego atrezji przewodu słuchowego zewnętrznego. W przypadkach jednostronnej atrezji z dobrym słuchem w drugim, prawidłowym uchu szybka interwencja niekoniecznie musi mieć miejsce, natomiast u dzieci z obustronną atrezją przewodu słuchowego wymagane jest szybkie zastosowanie odpowiednich metod leczniczych i rehabilitacyjnych zapewniających rozwój słuchu, mowy i języka. Istnieją doniesienia $\mathrm{z}$ tematycznych zjazdów międzynarodowych o operacji dziecka już dwumiesięcznego z obustronną atrezją przewodu słuchowego zewnętrznego i obustronną mikrocją (Colletti V., International Vibroplasty Symposium
2010 Toulouse, France, 15-17 April, 2010). Dla wielu, także dla nas postępowanie takie wydaje się jednak zbyt radykalne głównie ze względu na rozmiary urządzenia w porównaniu z rozmiarami główki dziecka oraz grubością tkanki kostnej oraz możliwością urazu okolicy implantu.

Istnieje wiele możliwych miejsc, które mogą być punktem zapięcia przetwornika FMT implantu. Należą do nich przede wszystkim odnoga długa kowadełka w niedosłuchach typu odbiorczego, pośrednia stymulacja okienka okrągłego [22] oraz bezpośrednia, bez użycia powięzi mięśnia skroniowego stymulacja w przypadkach po licznych nieudanych ossikuloplastykach czy operacjach radykalnych z dużą destrukcją elementów ucha środkowego w niedosłuchach typu przewodzeniowego czy mieszanego zaproponowana i wprowadzona przez prof. H. Skarżyńskiego w 2006 r. Inne sposoby, gdzie można umieścić przetwornik obejmują strzemiączko, płytkę strzemiączka, protezki do stapedotomii i ossikuloplastyki, odnogę krótką kowadełka (zastosowanie klasyczne), czy zdeformowany łańcuch albo pozostałości kosteczek. Wybór dość często podejmowany jest śródoperacyjnie, na podstawie stanu ucha środkowego oraz obecności poszczególnych kosteczek słuchowych. W przypadku istniejącego bloku kosteczek tak jak w opisywanym przypadku postępowanie może obejmować umieszczenie przetwornika na bloku odpowiednio uformowanych kosteczek lub też usunięcie bloku kowadełka i młoteczka z pozostawieniem strzemiączka i zaczepienie przetwornika bezpośrednio na strzemiączku [20]. Bezpośrednie frezowanie kosteczek może być przyczyną odbiorczego uszkodzenia słuchu zwłaszcza na wysokich częstotliwościach, co skłaniałoby do zastosowania tego drugiego rozwiązania, jednak wyniki nie potwierdziły takiego uszkodzenia słuchu. Według autorów, zachowanie istniejącego łańcucha kosteczek, nawet zdeformowanego, daje więcej opcji w przypadkach potencjalnych reoperacji, pozwala też na bardziej stabilne umieszczenie urządzenia a użycie niewielkiej ilości cementu szkłojonomerycznego stabilizuje dodatkowo układ polepszając przewodnictwo. Zawsze także, gdy stosuje się manipulacje na kosteczkach słuchowych podajemy dożylnie steroidy w dawkach leczniczych, co zapobiec ma odbiorczemu uszkodzeniu słuchu. 


\section{Wnioski}

Implant ucha środkowego Vibrant Soundbridge jest bardzo dobrym rozwiązaniem pozwalającym na poprawę słuchu w złożonej wadzie ucha zewnętrznego i środkowego w zespole Goltza-Gorlina. Wczesne i odległe wyniki audiologiczne są trwałe. Procedura otochirurgiczna wymaga dużego doświadczenia, które pozwoli w różnym stopniu niedorozwoju ucha środkowego na jego bezpieczne otwarcie, uruchomienie istniejącego w całości lub części łańcucha kosteczek słuchowych i bezinwazyjne umocowanie zakończenia elektrody stymulującej (przetwornika FMT).

\section{Piśmiennictwo:}

1. Liebermann S.: Atrophoderma linearis maculosa et papillomatosis congenitalis. Acta Dermatol Venereol, 1935; 16: 476-84

2. Goltz R.W., Peterson W.C., Gorlin R.J., Ravits H.G.: Focal dermal hypoplasia. Arch Dermatol. 1962; 86: 708-17

3. Gorlin R.J., Meskin L.H., Peterson W.C. Jr, Goltz R.W.: Focal dermal hypoplasia syndrome. Acta Derm Venereol, 1963; 43: 421-40

4. Warburg M.: Focal dermal hypoplasia. Ocular and general manifestations with a survey of the literature. Acta Ophthalmol (Copenh), 1970; 48(3): 525-36

5. Sacoor M.F., Motswaledi M.H.: Three cases of focal dermal hypoplasia (Goltz syndrome). Clin Exp Dermatol, 2005; 30(1): 35-37

6. Temple I.K., MacDowall P., Baraitser M., Atherton D.J.: Focal dermal hypoplasia (Goltz syndrome). J Med Genet, 1990; 27(3): 180-87

7. Gottlieb S.K., Fisher B.K., Violin G.A.: Focal dermal hypoplasia. A nine-year follow-up study. Arch Dermatol, 1973; 108(4): 551-53

8. Gündüz K., Günalp I., Erden I.: Focal dermal hypoplasia (Goltz's syndrome). Ophthalmic Genet, 1997; 18(3): 143-49

9. Goltz R.W.: Focal Dermal Hypoplasia Syndrome epub, eMedicine Update: Jul 30, 2008

10. Skarzynski H, Podskarbi-Fayette R: Treatment of otorhinolaryngological manifestations of three rare genetic syndromes: Branchio-Oculo-Facial (BOF), Ectrodactyly Ectodermal dysplasia Clefting (EEC) and focal dermal hypoplasia (Goltz syndrome). Int J Pediat Otorhinolaryngology, 2009; 73(1): 143-51

11. Grzeschik KH, Bornholdt D, Oeffner F i wsp.: Deficiency of PORCN, a regulator of Wnt signaling, is associated with focal dermal hypoplasia. Nat Genet, 2007; 39(7): 833-35

12. Wang X, Reid Sutton V, Omar Peraza-Llanes J i wsp.: Mutations in X-linked PORCN, a putative regulator of Wnt signaling, cause focal dermal hypoplasia. Nat Genet, 2007; 39(7): 836-38

13. Wettke-Schäfer R, Kantner G: X-linked dominant inherited diseases with lethality in hemizygous males. Hum Genet, 1983; 64(1): 1-23

14. Toro-Sola MA, Kistenmacher ML, Punnett HH, DiGeorge AM: Focal dermal hypoplasia symdrome in a male. Clin Genet, $1975 ; 7(4)$ : 325-27
15. Fjellner B: Focal dermal hypoplasia in a 46, XY male. Int J Dermatol, 1979; 18(10): 812-15

16. Büchner SA, Itin P: Focal dermal hypoplasia syndrome in a male patient. Report of a case and histologic and immunohistochemical studies. Arch Dermatol, 1992; 128(8): 1078-82

17. Seven M, Suyugül Z, Yüksel A i wsp.: A family presenting Goltz syndrome (focal dermal hypoplasia) in three generations. Turk J Pediatr, 1998; 40(4): 593-601

18, Gorski JL: Father-to-daughter transmission of focal dermal hypoplasia associated with nonrandom X-inactivation: support for X-linked inheritance and paternal X chromosome mosaicism. Am J Med Genet, 1991; 40(3): 332-37

19. Frenzel H, Hanke F, Beltrame M i wsp.: Application of the Vibrant Soundbridge to unilateral osseous atresia cases. Department of Otorhinolaryngology, University Hospital Schleswig-Holstein, Lübeck, Germany

20. Frenzel H, Hanke F, Beltrame M, Wollenberg B: Application of the Vibrant Soundbridge in bilateral congenital atresia in toddlers. Acta Otolaryngol, 2010; 130(8): 966-70

21. Roman S, Nicollas R, Triglia JM: Eur Ann Otorhinolaryngol Head Neck Dis. Middle ear implant for mixed hearing loss with malformation in a 9-year-old child. 2010; 127(1): 11-14

22. Colletti V, Soli SD, Carner M, Colletti L: Treatment of mixed hearing losses via implantation of a vibratory transducer on the round window. Int J Audiol, 2006; 45(10): 600-8

23. Skarzynski H., PorowskiM., Lazecka K.: Application of middle ear implant Vibrant Soundbridge in congenital ear deformations in children. The $10^{\text {th }}$ International Congress of the European Society of Pediatric Otorhinolaryngology Pamplona, Spain, 5 to 8 June 2010

24. Porowski M., Skarzynski H., Mrowka M. i wsp.: Application of middle ear implant Vibrant Soundbridge in congenital ear deformations in children. The $10^{\text {th }}$ EFAS Congress, June 22-25 Warsaw, Poland

25. Skarzynski H.: Direct Round Window Stimulation with the Med-El Vibrant Soundbridge: 5-Years Experience Using Technique Without Fascia. Combined Otolaryngology Spring Meeting, San Diego, USA, 18-22.04.2012 